\title{
Magnesium Oxide Supported Bimetallic Pd/Cu Nanoparticles as an Efficient Catalyst for Sonogashira Reaction
}

\author{
Mohammad Gholinejad $^{*}$, Maedeh Bahrami ${ }^{\mathrm{a}}$, Carmen Nájera* ${ }^{\mathrm{b}}$, Biji Pullithadathil ${ }^{\mathrm{c}}$ \\ ${ }^{a}$ Department of Chemistry, Institute for Advanced Studies in Basic Sciences (IASBS), P. O. Box \\ 5195-1159, Gavazang, Zanjan 45137-6731, Iran. Email: gholinejad@iasbs.ac.ir; ${ }^{\mathrm{b}}$ Departamento \\ de Química Orgánica and Centro de Innovación en Química Avanzada (ORFEO-CINQA). \\ Universidad de Alicante, Apdo. 99, E-03080-Alicante, Spain. Email: \\ cnajera@ua.es; 'Department of Chemistry, PSG College of Technology, Coimbatore-641004, \\ INDIA,
}

Abstract: $\mathrm{PdCu}$ bimetallic nanoparticles with a diameter of about $3 \mathrm{~nm}$ are prepared and supported on a polymeric vinylimidazole ligand modified magnesium oxide. This new material is characterized using different analysis such as XRD, XPS, CHNS, TEM, SEM, and EDXmapping. PdCu supported on $\mathrm{MgO}$ ( $\mathrm{MgO} @ \mathrm{PdCu}$ ) exhibits high catalytic activity in the Sonogashira coupling reaction of aryl iodides, bromides and chlorides with low Pd loading (0.05 to $0.2 \mathrm{~mol} \%)$. This catalyst is recovered and recycled for 11 consecutive runs preserving its catalytic activity in the model reaction of iodobenzene with phenylacetylene for at least 8 cycles. Reused catalyst is characterized with TEM, XPS and EDX showing preservation of the catalyst structure. Using hot filtration and PVP poisoning tests, the catalyst shows a heterogeneous behavior for the model reaction. 


\section{1- Introduction}

The Sonogashira-Hagihara reaction is one of the most important methodology for the bond formation between sp carbon and $\mathrm{sp}^{2}$ carbon atoms forming substituted aryl-alkynes and conjugated enynes through the coupling of aryl and vinyl halides or triflates with terminal alkynes, respectively, by palladium catalysis and in the presence of copper(I) as co-catalyst [111]. The obtained products from the Sonogashira reaction have wide utility in modern organic chemistry and have been extensively applied in the synthesis of natural products and pharmaceuticals, as well as in material science [12-14]. In recent years, different copper-free Sonogashira protocols (the original Cassar-Heck version of this reaction) have been reported [15-19]. However, it has been proved that in many cases, this cross-coupling reaction could be accelerated in thepresence of copper under oxygen free conditions to prevent the formation of diynes as homo-coupling products [1-11].

Recently, an increasing attention has been paid to the application of bimetallic catalysts in different organic transformations. Due to new electronic and chemical properties of bimetallic catalysts compared to the monometallic systems, high catalytic activity and selectivity are expected for target products in these bimetalllic catalyzed reactions [20-22]. Among the different bimetallic catalysts, $\mathrm{Pd} / \mathrm{Cu}$ catalysts have attracted great attentions in different organic transformations [23-43].Along this line, some efforts have been recently paid to use homogeneous or heterogeneous $\mathrm{PdCu}$ bimetallic catalysts in various organic transformations particular in Sonogashira reaction under efficient and enhanced catalytic activity conditions [4467].Due to the expensive price and toxicity of Pd, many efforts have been recently devoted to develop very efficient heterogeneous and recyclable palladium catalysts in different organic reactions [68-75], especially in the synthesis of pharmaceuticals in which allowable content of 
Pd is $<5$ ppm [76]. For this purpose, different solid supports such as polymers [77], silica [7879], and naturally occurring polysaccharides [80] have been used for stabilization of $\mathrm{Pd}$ nanoparticles in different coupling reactions.

Concerning solid supports, metal oxides have received much attention as resourceful materials for design of new heterogeneous catalysts [81-82]. Along this line, $\mathrm{MgO}$ an organic ceramic material with different properties such as high concentration of reactive surface ions acting as Lewis acids, lattice bound and isolated hydroxyl groups and anionic and cationic vacancies, is considered as a promising support for the preparation of heterogeneous Pd catalysts [83-105]. For instance, nanocrystalline MgO supported palladium nanoparticles [NAP-Mg-Pd(0)] has been used as catalyst for the selective reduction of nitro compounds [90], Heck reaction of heteroaryl bromides [91], and oxidative coupling between $N$-aryl-2-aminopyridines and alkynes in the presence of copper(II) chloride as additive [92]. In addition, Pd NPs supported on MgO have been used for the regioselective hydrogenation of quinolines, alkenes, and biodiesel under

mild reaction conditions [93]. However, to the best of our knowledge there is no report on using $\mathrm{MgO}$ as support for the stabilization of bimetallic $\mathrm{PdCu}$ nanoparticles in any organic transformations. In this work, we introduce imidazole as a simple nitrogen ligand modified MgO as an excellent support for $\mathrm{PdCu}$ nanoparticles stabilization and the application of this new material as a simple and efficient catalyst for Sonogashira coupling reactions of aryl halides with terminal alkynes under efficient and phosphine-free conditions.

\section{Experimental}

\subsection{Synthesis of $\mathrm{MgO}$ particles}

In a $250 \mathrm{~mL}$ flask, $\mathrm{Mg}\left(\mathrm{NO}_{3}\right)_{2}$ (3 g) was dissolved in distilled water (100 mL) and an aqueous solution of $\mathrm{Na}_{2} \mathrm{CO}_{3}(1.6 \mathrm{~g}$ in $100 \mathrm{~mL})$ was added slowly. The obtained mixture was then stirred 
vigorously for $12 \mathrm{~h}$ at room temperature. After centrifugation, the resulting solid was isolated and dried at $100{ }^{\circ} \mathrm{C}$. For achieving the fine powder of MgO, the obtained solid was calcinated at $400{ }^{\circ} \mathrm{C}$ for $2 \mathrm{~h}$.

\subsection{Synthesis of imidazole functionalized $\mathrm{MgO}$}

Acryloyl chloride (5 mmol, $0.4 \mathrm{~mL})$ and $\mathrm{Et}_{3} \mathrm{~N}(8 \mathrm{mmol}, 1.1 \mathrm{~mL})$ were added to the synthesized MgO (1g), which was sonicated in THF $(15 \mathrm{~mL})$, at $0{ }^{\circ} \mathrm{C}$ under an argon atmosphere. Then, the mixture was subjected to centrifugation and the obtained isolated solid was washed with distilled water $(2 \times 15 \mathrm{~mL})$ and ethanol $(2 \times 15 \mathrm{~mL})$ and then dried in an oven at $70{ }^{\circ} \mathrm{C}$. For introducing the imidazole group, $\mathrm{MgO}(1 \mathrm{~g})$ was dissolved in $\mathrm{EtOH}(20 \mathrm{~mL})$ and the mixture was deoxygenated by bubbling argon for $5 \mathrm{~min}$. Then, $N$-vinilimidazole ( $5 \mathrm{mmol}, 0.45 \mathrm{~mL}$ ) and benzoyl peroxide ( 6 mg) were added to the previously achieved mixture and the nit was refluxed at $80{ }^{\circ} \mathrm{C}$ for $24 \mathrm{~h}$. After centrifugation, the obtained solid was washed with water $(15 \mathrm{~mL})$ and dichloromethane $(3 \times 15 \mathrm{~mL})$ and dried at $60{ }^{\circ} \mathrm{C}$.

\subsection{Synthesis of bimetallic $\mathrm{MgO} @ P d C u$}

$\mathrm{CuSO}_{4} .5 \mathrm{H}_{2} \mathrm{O}(18 \mathrm{mg}, 0.07 \mathrm{mmol})$ was dissolved in a solution of ethylene glycol $(5 \mathrm{~mL})$ and polyvinylpyrrolidone (200 mg) and the mixture was stirred for $2 \mathrm{~h}$ at $80{ }^{\circ} \mathrm{C}$ under an argon atmosphere. In another flask, $\mathrm{Pd}(\mathrm{OAc})_{2}$ (32 mg, 0.16mmol) and polyvinylpyrrolidone (400 mg) were dissolved in dioxane $(5 \mathrm{~mL})$ and stirred for $2 \mathrm{~h}$ at room temperature under argon atmosphere. The obtained solution was mixed with the $\mathrm{CuSO}_{4} \cdot 5 \mathrm{H}_{2} \mathrm{O}$ solution and mechanically stirred under an argon atmosphere. During the stirring, a solution of $\mathrm{NaOH}\left(1 \mathrm{~mol} \cdot \mathrm{L}^{-1}\right)$ was added upon reaching $\mathrm{pH}$ to 9-10 and the obtained mixture was stirred for $2 \mathrm{~h}$ at $100{ }^{\circ} \mathrm{C}$. Then, the reaction mixture was cooled to room temperature and the resulting suspension was concentrated 
to $5 \mathrm{~mL}$ by centrifugation (10000 rpm, $10 \mathrm{~min})$. The obtained suspension was diluted with acetone (5 mL) and the mixture was added to the prepared imidazole functionalized MgO (1 g), which was previously sonicated in acetone $(10 \mathrm{~mL})$. The mixture was stirred at room temperature for $24 \mathrm{~h}$ under argon atmosphere and subjected to centrifugation. The resulting solid was washed with water $(3 \times 10 \mathrm{~mL})$ and dichloromethane $(3 \times 10 \mathrm{~mL})$ and dried at $100{ }^{\circ} \mathrm{C}$ affording MgO@PdCu.

\subsection{General procedure for Sonogashira reaction}

To a 5 mL flask, the catalyst MgO@PdCu (10 mg for ArI or 40 mg for ArBr and ArCl), ArX (1 mmol), DABCO (168 mg, $1.5 \mathrm{mmol}$ ), and TBAB (322 mg, $1 \mathrm{mmol}$ ), for aryl chloride and DMF (2 mL) were added under argon atmosphere. The alkyne (1.5 mmol) was also added and the resulting mixture was stirred at $60-120{ }^{\circ} \mathrm{C}$ for appropriate reaction times (see Tables). Progress of reactions was followed by GC. Then, the reaction mixture was cooled down to room temperature and extracted with ethyl acetate $(3 \times 5 \mathrm{~mL})$, the organic phase was washed with $\mathrm{H}_{2} \mathrm{O}$ (10 mL), dried and evaporated. The resulting residue was purified by column or plate chromatography using hexane and ethyl acetate as eluents.

2.5.Typical procedure for recycling of the catalyst for the reaction of iodobenzene and phenyl acetylene

After stirring the reaction in each run for $24 \mathrm{~h}$ and studying of GC yield, the reaction mixture was centrifuged and the obtained solid was washed with ethyl acetate and dried. The resulting solid was used for another batch of reaction under the optimized reaction conditions. This process was repeated for 11 consecutive runs (see, Figure 9).

\section{Results and discussion}




\subsection{Materials and characterization}

The preparation of MgO@PdCu is summarized in scheme 1. MgO was prepared by treatment of $\mathrm{Mg}\left(\mathrm{NO}_{3}\right)_{2}$ with $\mathrm{Na}_{2} \mathrm{CO}_{3}$ in $\mathrm{H}_{2} \mathrm{O}$ and further calcination at $400{ }^{\circ} \mathrm{C}$. Then, acryloyl chloride was added in dry THF and the resulting solid was allowed to react with vinylimidazole in the presence of benzoyl peroxide. To this MgO bonded to the polymer containing imidazole, was added the bimetallic PdCu nanoparticles in acetone.
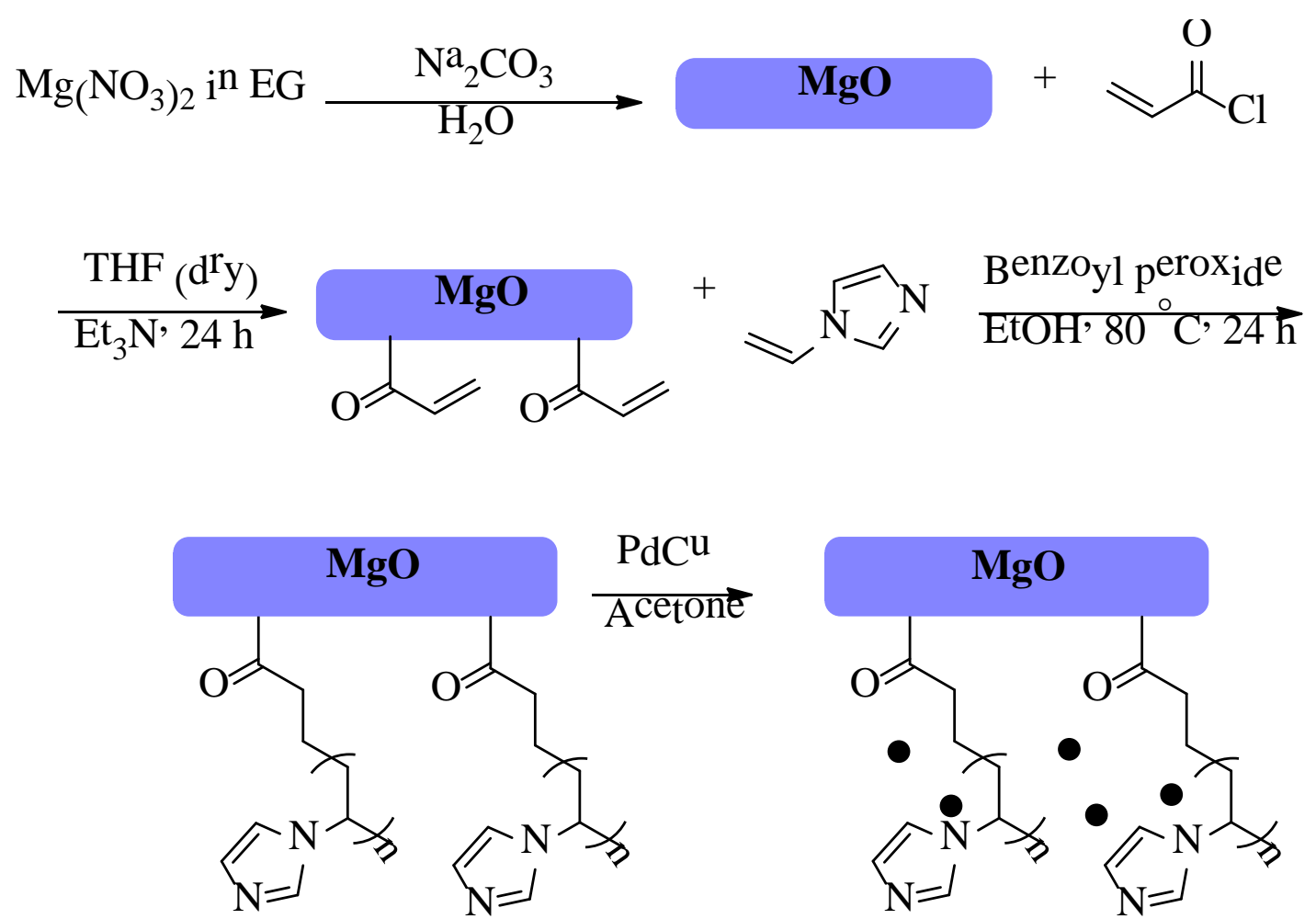

Scheme 1: Synthetic steps for the preparation of MgO@PdCu.

In the first step, the formation of $\mathrm{MgO}$ was confirmed using X-ray powder diffraction (XRD) showing related peaks to $\mathrm{MgO}$ in $2 \theta=37,43.1,62.4,75.1,78.7$ [106] and small peaks in $2 \theta=30.3$ and 38.2correspond to $\mathrm{Na}_{2} \mathrm{CO}_{3}$ [107] and $\mathrm{Mg}(\mathrm{OH})_{2}$ [108] impurities (Figure1). 


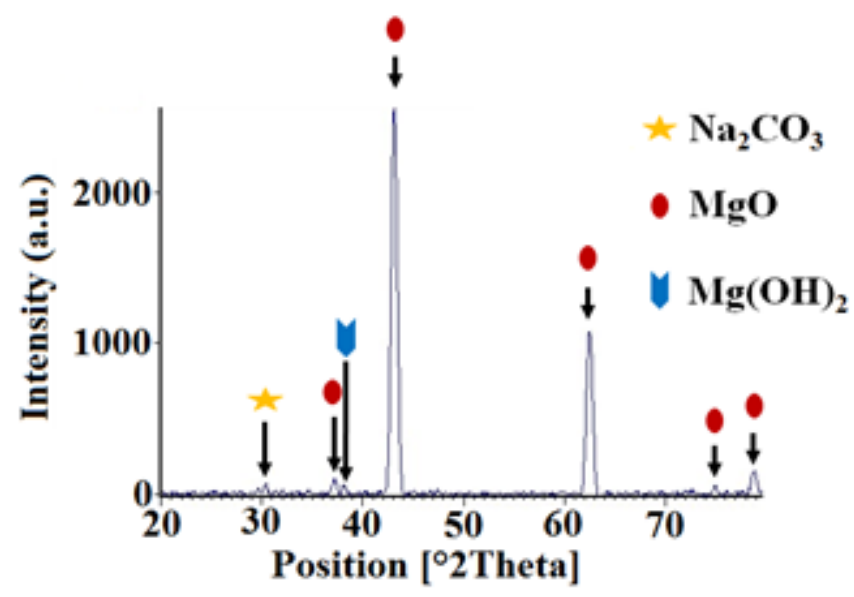

Figure1: XRD pattern of prepared MgO.

Then, the acryloyl functionalized MgO was polymerized with vinyl imidazole to introduce nitrogen ligands on $\mathrm{MgO}$. Because imidazole is considered as excellent ligand for coordination and stabilization of different transition metals [109], vinylimidazole was added for copolymerization with the acryloyl unit. After addition of fresh prepared bimetallic $\mathrm{PdCu}$ nanoparticles, $\mathrm{MgO} @ \mathrm{PdCu}$ was obtained containing 0.05 and $0.01 \mathrm{mmol} \cdot \mathrm{g}^{-1} \mathrm{Pd}$ and $\mathrm{Cu}$, respectively, which has been determined by atomic absorption spectroscopy. Elemental analysis of $\mathrm{MgO} @ \mathrm{PdCu}$ showed a nitrogen content of 1.85\%. According to this result the degree of introduced imidazole in the $\mathrm{MgO}$ support was calculated to be $0.65 \mathrm{mmol} \cdot \mathrm{g}^{-1}$.

Figure 2(a-d) shows the TEM image analysis of PdCu nanoparticles before anchoring onto MgO nanosheet supports. The HR-TEM analysis (Fig. 2(b-c)) shows the presence of lattice fringes with a d-spacing value of $0.225 \mathrm{~nm}$ and $0.21 \mathrm{~nm}$ corresponding to the (111) plane of Pd and (111) plane of CuPd. Figure 2b represents the inverse FFT of the selected area which indicated two distinguishable periodic lattice fringes, corresponding to CuPd and Pd and clearly validates the formation of PdCu bimetallic nanoparticles. According to first principles studies, during the formation of $\mathrm{PdCu}$ bimetallic nanoparticles, the electron donor atom, such as $\mathrm{Cu}$ and 
an electron-acceptor, such as Pd, the d-band of Pd is lowered and the local electronic properties will be more similar to Pt and such materials, composed of electron donor and acceptor metals, can exhibit desirable catalytic properties. [110]
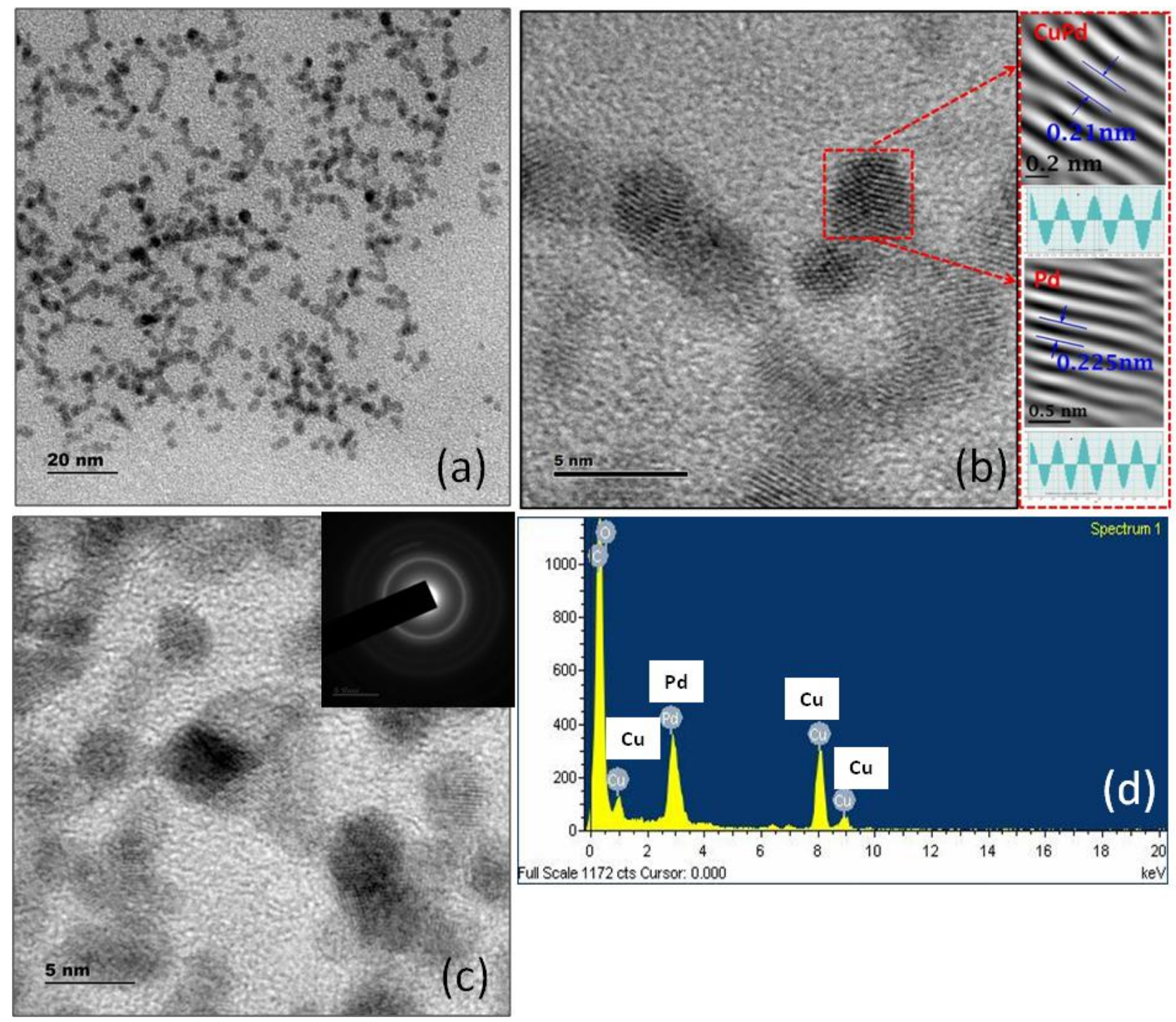

Figure 2: (a-c) Representative TEM and HRTEM images, (Insets in (b) shows the inverse FFT patterns of the selected area and (c) shows the corresponding SAED pattern) and (d) corresponding EDS spectrum of unsupported PdCu nanoparticles. 
However, TEM images of $\mathrm{PdCu}$ nanoparticles before addition to $\mathrm{MgO}$ nanosheets, showed slightly aggregated chain-like structure confirming the effect of imidazole modified MgO in stabilization of PdCu nanoparticles (Figure 3). Figure 3(a-d) reveals the effective anchoring of $\mathrm{PdCu}$ particles on the surface of $\mathrm{MgO}$ nanosheets. It is interesting to note that the $\mathrm{PdCu}$ nanoparticles were found to be highly uniform, monodispersed with particle size in the range of 3-4 nm after anchoring onto MgO nanosheets. Fig. 3f shows the selected area diffraction pattern (SAED) analysis with prominent ring patterns corresponding to the fcc CuPd structure (JCPDS no. 48-1551) and cubic MgO (JCPDS no. 75-1585). The diffraction pattern shows prominent rings with interplanar spacing of $0.275 \mathrm{~nm}, 0.235 \mathrm{~nm}$ and $0.146 \mathrm{~nm}$ corresponding to the (111), (200) and (311) of $\mathrm{MgO}$ and interplanar spacing of $0.211 \mathrm{~nm}, 0.133 \mathrm{~nm}$ and $0.100 \mathrm{~nm}$ corresponding to the (111) of CuPd. The (111) plane of CuPd and (111) plane of Pd [JCPDS No: 46-1043] matched well with the SAED pattern revealing the existence of PdCu bimetallic nanoparticles on $\mathrm{MgO}$. The preferential growth plane of $\mathrm{MgO}$ was found to be (111) as confirmed from SAED. EDS spectra of the unsupported (Figure 2d) and MgO supported (Figure 3e) $\mathrm{PdCu}$ bimetallic nanoparticles clearly give evidence for the presence of $\mathrm{Cu}, \mathrm{Pd}$ and $\mathrm{MgO}$ in the samples. 

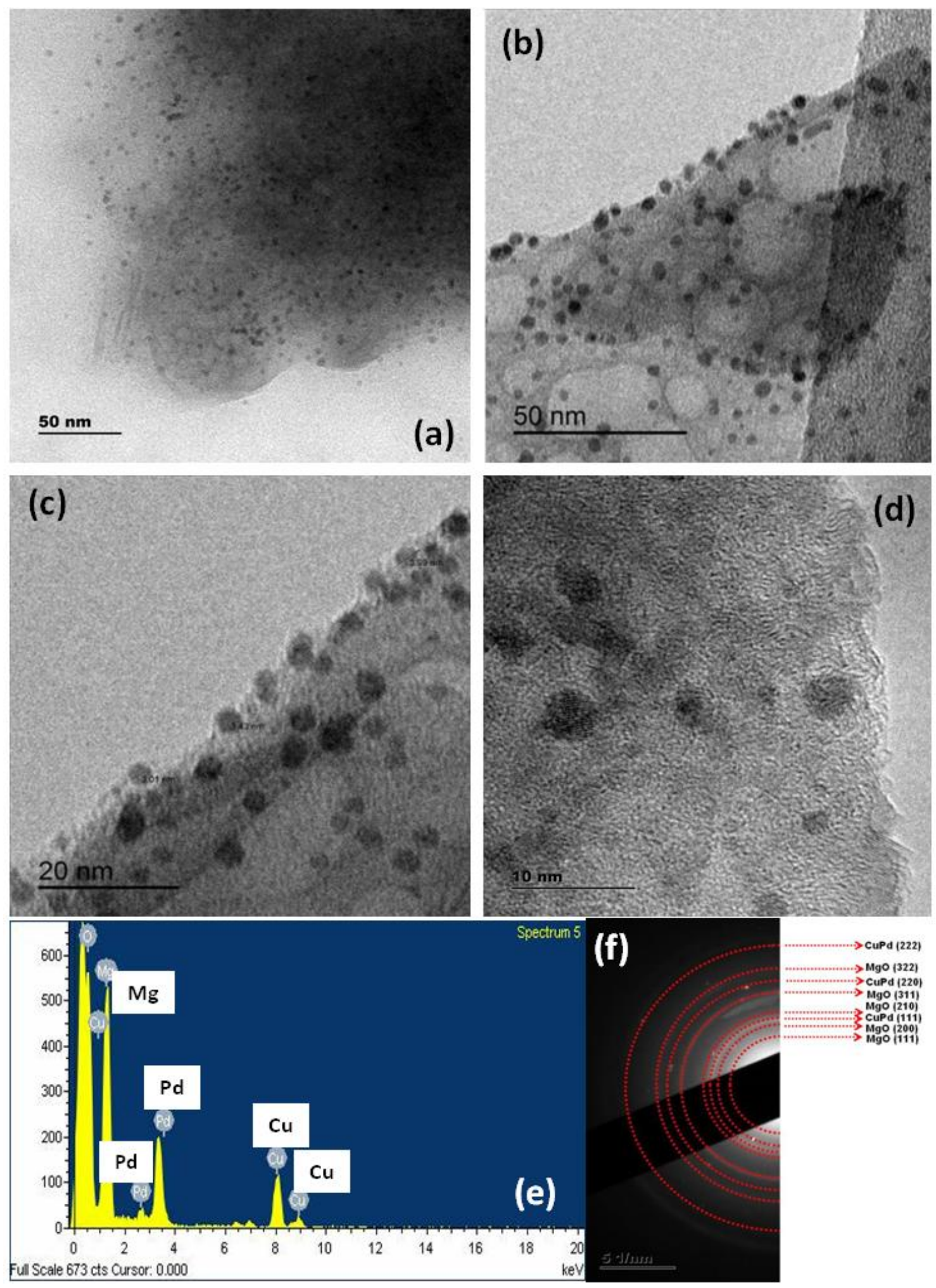

Figure 3: (a-d) Representative TEM and HRTEM images, (e) corresponding EDS spectrum and (f) SAED pattern of MgO@PdCu. 


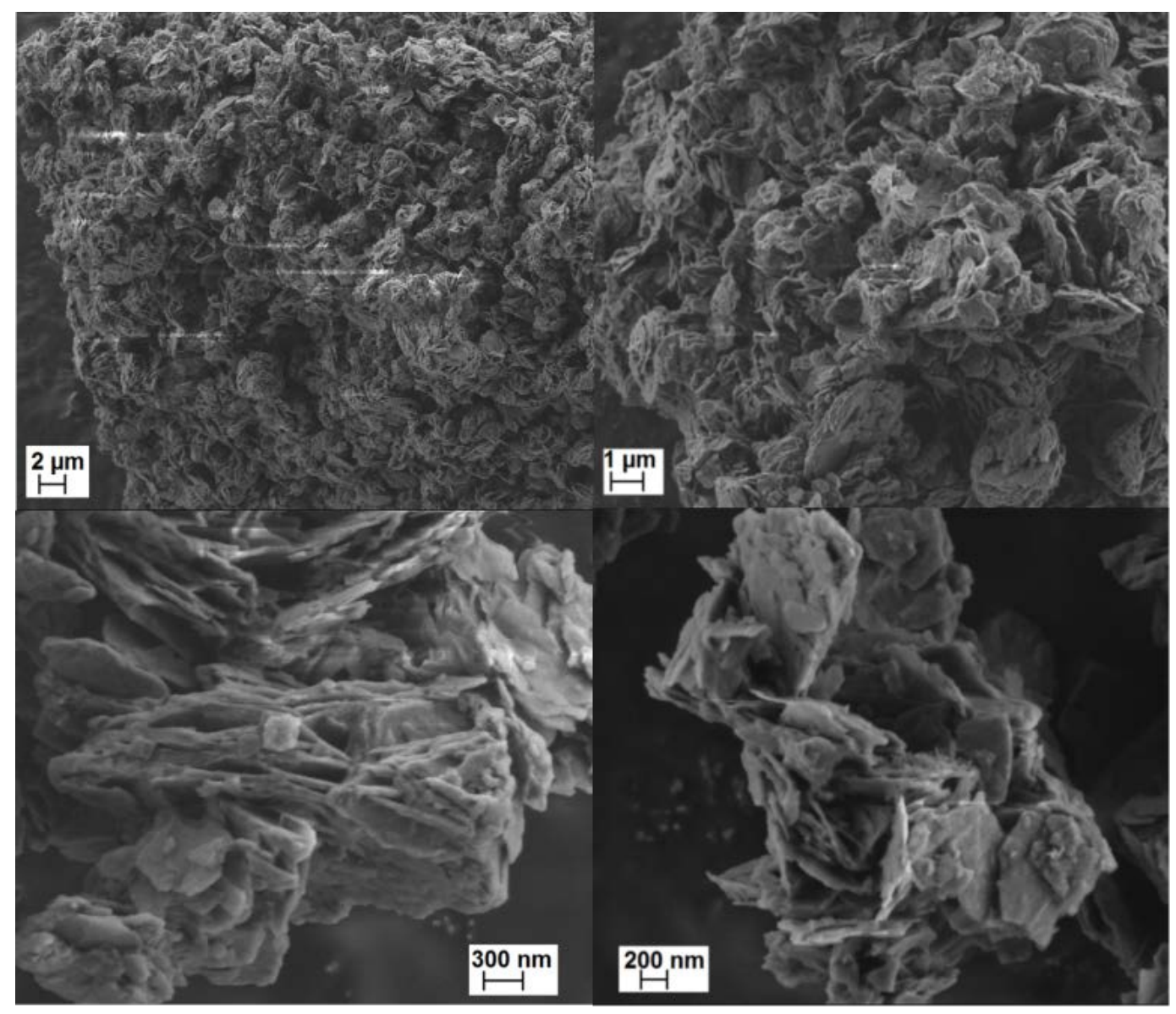

Figure 4: SEM images of MgO@PdCu in different magnifications.

EDS mapping images of the material MgO@PdCu was also studied (Figure 1, ESI).It can be seen that both $\mathrm{Pd}$ and $\mathrm{Cu}$ are mostly distributed evenly throughout each PdCu species, suggesting an alloy structure[111-113]. Furthermore, energy-dispersive X-ray spectroscopy (EDS) analysis of MgO@PdCu confirmed the presence of Pd, Cu, Mg and N species (Figure 2, ESI).

In order to investigate the oxidation states of $\mathrm{Pd}$ and $\mathrm{Cu}$ in the solid support, $\mathrm{X}$-ray photoelectron spectroscopy (XPS) of the MgO@PdCu was performed (Figure 5). High resolution XPS analysis of Pd region showed three doublets between 335-343 eV. An intense doublets at 335 and $340 \mathrm{eV}$ were related to $\mathrm{Pd}(0)$ and a doublet peak at 336.5 and $341.6 \mathrm{eV}$ related to $\mathrm{Pd}(\mathrm{II})$ in $\mathrm{PdO}$ form.A doublet peak in higher binding energy at 338 and $343 \mathrm{eV}$ could be assigned to the Pd(IV) species 
in $\mathrm{PdO}_{2}$ form (Figure 5a)[114-116].These results indicated that $44 \%$ of $\mathrm{Pd}$ are in $\mathrm{Pd}(0)$ oxidation state, $32 \%$ as $\mathrm{PdO}$ and $24 \%$ as $\mathrm{PdO}_{2}$ form. Formation of $\mathrm{Pd}(0)$ may resulted from the addition of concentrate electron rich polyethylene glycol and polyvinylpyrrolidone and oxidized palladium are the results of the reaction with sodium hydroxide at high temperatures under the catalyst preparation steps.

XPS spectra of $\mathrm{Cu} 2 \mathrm{p}$ region showed two peaks centered at 932.8 and $952.9 \mathrm{eV}$ which were assigned to $\mathrm{Cu} 2 \mathrm{p} 3 / 2$ and $\mathrm{Cu} 2 \mathrm{p} 1 / 2$ of $\mathrm{CuO}$, respectively[116-118] (Figure 5b). The small peak at the binding energy of 935.1 was assigned to the presence of $\mathrm{Cu}(\mathrm{OH})_{2}$ species [119].Apart from the main peaks ofCuO, three extra shake-up satellite peaks were observed in higher binding energies at 941.7, 943.8, 954.8 which can be attributed to $\mathrm{Cu}(\mathrm{II})$ states in $\mathrm{CuO}$ and $\mathrm{Cu}(\mathrm{OH})_{2}$ [117-120]. The spectra also showed two smaller peaks at 931.5 and 951.5 which correspond to $\mathrm{Cu}_{2} \mathrm{O}$ or $\mathrm{Cu}$ species.Since binding energies of $\mathrm{Cu}(0)$ and $\mathrm{Cu}_{2} \mathrm{O}$ are very close and are different by only $0.1 \mathrm{eV}$, detection of true species by using this region ofbinding energy is very difficult[117-120]. Therefore, we studied itby LMM auger transition spectroscopy in the XPS spectra and it was found out to be $568 \mathrm{eV}$ for $\mathrm{Cu}(0)$ and $570 \mathrm{eV}$ for $\mathrm{Cu}_{2} \mathrm{O}$ species [121-122]. Fitting of these XPS data in this region showed apearence of a peak at $570 \mathrm{eV}$ confirming the peak in $931.5 \mathrm{eV}$ is related to $\mathrm{Cu}_{2} \mathrm{O}$ species (Figure 3, ESI). XPS studies of Mg [123] region confirmed the presence of $\mathrm{Mg}$ by showing related peaks to $\mathrm{MgO}$ at $1304 \mathrm{eV}$ (Figure5c). Furthermore, XPS analysis in N1s region confirm the presence of imidazole by two peaks at 398.9 and $401.02 \mathrm{eV}$ which can be attributed to the $\mathrm{C}=\mathrm{N}$ and $\mathrm{C}-\mathrm{N}$ bonds of the imidazole (Figure 5d) [124-125]. 


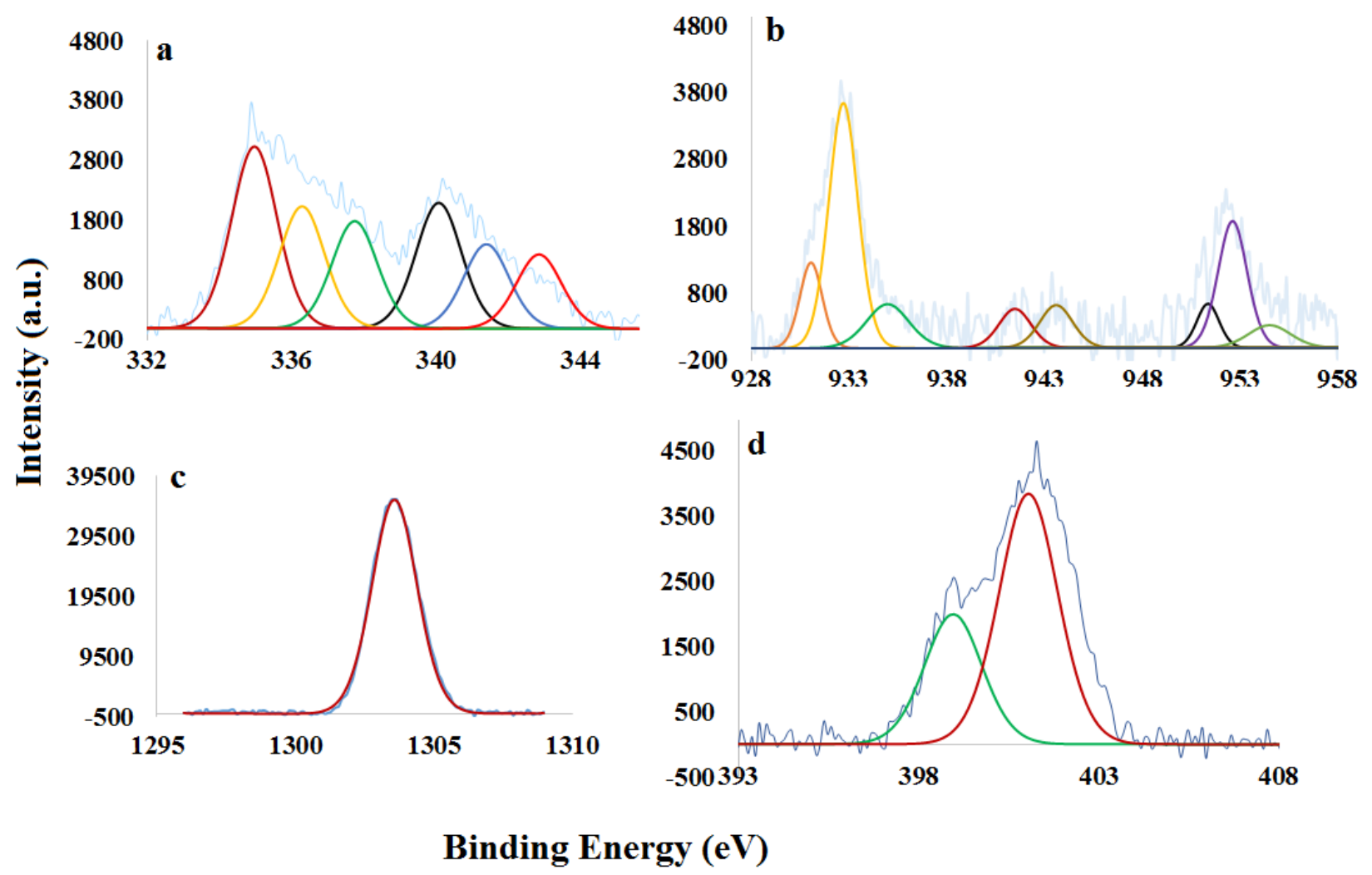

Figure 5: XPS spectra of MgO@PdCu in a) Pd 3d, b) Cu 2p, c) Mg 1s and d) N 1s regions.

XRD pattern of the PdCu suspensions before stablizationon MgOwere also studied (Figure 6). The XRD diffractogram of MgO@PdCu showed related peaks to $\mathrm{MgO}$ at 36.7, 42.9, 62.2, 74.5 and 78.5 [106] and a peak at 34.3 which is related to formation of perovskite structure $\left(\mathrm{Mg}_{7} \cdot 0_{4} \mathrm{C}_{4 \cdot 00} \mathrm{O}_{20.00}\right)[126]$ (Figure 6a). However, this diffractogram did not show any significant peaks for $\mathrm{Cu}$ and $\mathrm{Pd}$ due to low loading weight of them and the overlap of MgO peaks with PdCu peaks. Therefore, we studied XRD of $\mathrm{PdCu}$ suspension before stabilization on $\mathrm{MgO}$ support (Figure 6b).

Expanded XRD of PdCu suspension before stablization on MgO showed the presence of peaks at 2theta value of $23.3^{\circ}$, which is matched with (021) planes of $\mathrm{Cu}(\mathrm{OH})_{2}$ [127] (Figure 6c). These spectra also showed the presence of peaks at $24^{\circ}, 34^{\circ}$ and $39.9^{\circ}$, which correspond to the lattice 
planes of (101), (110) and (110) of $\mathrm{Cu}_{3} \mathrm{Pd}$. (JCPDS no.07-0138) (Figure 6c,d). These results indicated the presence of peaks at $29.1^{\circ}$ and $36.2^{\circ}$, which are related to the plane (110) and (111) of $\mathrm{Cu}_{2} \mathrm{O}$ [128] (Figure 8c). The peaks at 2theta $=32.2$, 35.5 and 38.5 were ascribed to the (110), (002), and (200) reflections of $\mathrm{CuO}$ [129] (Figure 8c,d). In addition,the apperence of a peak at 2theta value of $41.7^{\circ}$ is related to the lattice plane (110) of CuPd (JCPDS no. 48-1551) (Figure 8d). Furthermore, peaks related to Pd were observed at 2theta value of $40.5^{\circ}$ and $46.3^{\circ}$, which correspond to (220) plane of Pd [130] (Figure 6c,d).

(a)

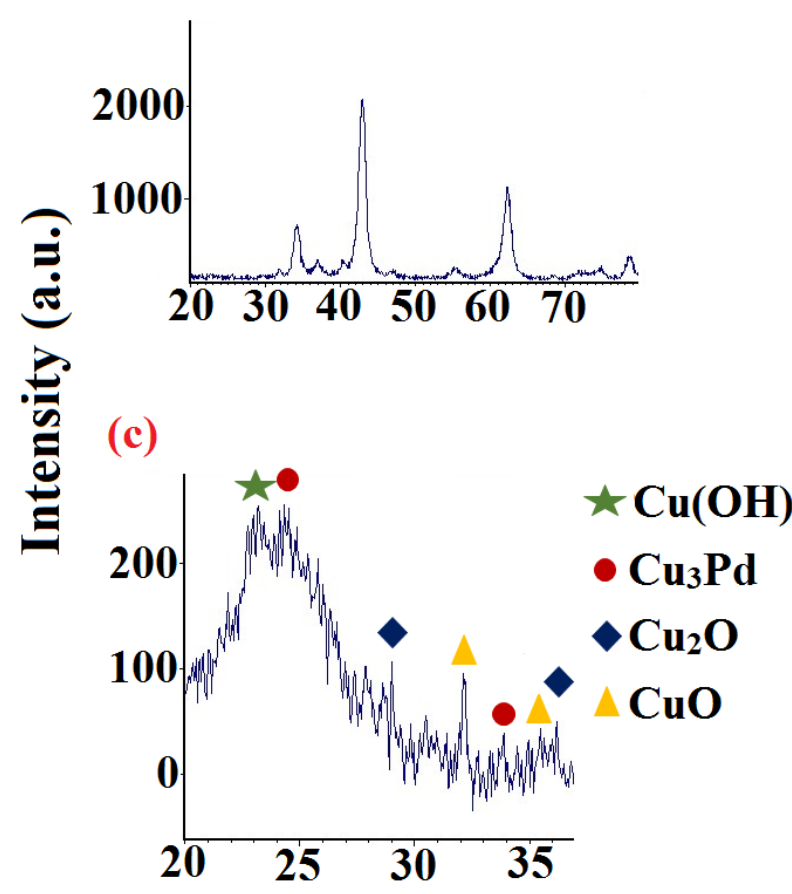

(b)

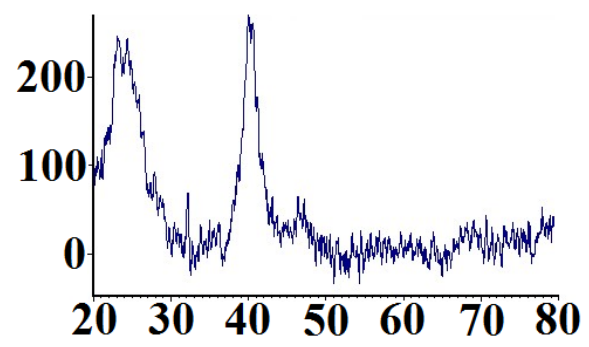

(d)

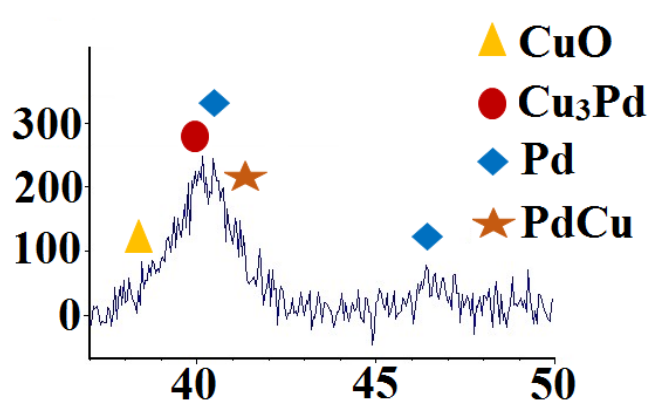

Position [ ${ }^{\circ}$ 2Theta]

Figure 6: XRD spectra of: a) MgO@PdCu, b) PdCu suspension in 20: 20-80 c) PdCu suspension in 20: 20-37 d) PdCu suspension in 20: 37-50.

\subsection{Catalytic performance}


Catalytic activity of prepared PdCu catalyst was studied in Sonogashira alkynylation reaction of aryl halides with terminal alkynes. Initially, for finding optimized reaction conditions, the reaction of iodobenzene with phenylacetylene was selected as a model reaction and effect of different factors such as solvent, reaction temperature and catalyst loading were studied. Using water as solvent and different bases such as DABCO, $\mathrm{K}_{2} \mathrm{CO}_{3}, t$-BuOK, $\mathrm{Et}_{3} \mathrm{~N}$, and $\mathrm{K}_{3} \mathrm{PO}_{4}$ in the presence of $0.1 \mathrm{~mol} \%$ Pd loading, gave very low yields for this reaction (Table 1, entries 1-5). By changing the solvent to DMF and using different bases (Table 1, entries 6-10), the yields were improved. The best results were obtained using DABCO as a base (Table1, entry 6). Using DABCO in other solvents such as $\mathrm{CH}_{3} \mathrm{CN}$, EtOH, or toluene gave lower yields (Table 1, entries 11-13). By increasing the reaction temperature to $60{ }^{\circ} \mathrm{C}$ and using DABCO and DMF, yield of this reaction was increased to $98 \%$ (Table 1, entry 14). However, in order to insure about Pd loading, this model reaction was performed in the presence of 0.05 and $0.025 \mathrm{~mol} \%$ of Pd and results indicate the formation of the desired products in $97 \%$ and $63 \%$ yield, respectively (Table 1, entries 15 and 16). Therefore, we selected $0.05 \mathrm{~mol} \%$ of Pd, DABCO as a base and DMF as solvent at $60{ }^{\circ} \mathrm{C}$ to be most efficient and optimized reaction conditions (Table 1 , entry 15). It is worth mentioning thatfor showing the important effects of the both $\mathrm{Cu}$ and $\mathrm{Pd}$ in the reaction efficiency, the model reaction in the presence of similar catalyst without $\mathrm{Cu}$ and also without Pdwere studied. The corresponding results indicated that only 37 and 8\% GC yield were obtained, respectively (Table 1, entries 17 and 18).

Table 1. Optimization of reaction condition for the coupling of iodobenzene and phenylacetylene catalyzed by $\mathrm{MgO} @ \mathrm{PdCu}^{\left[{ }^{[a]}\right.}$ 


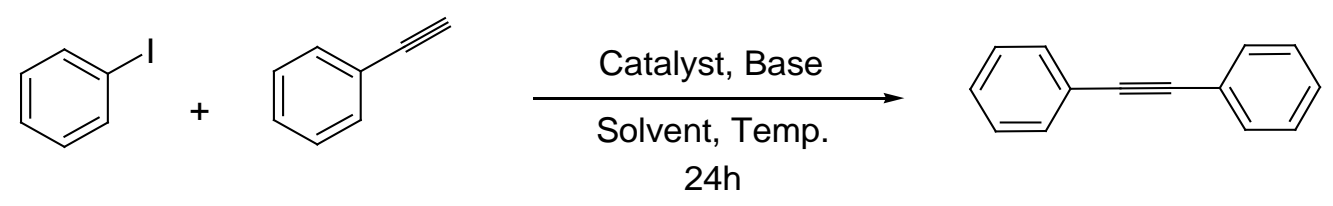

\begin{tabular}{|c|c|c|c|c|c|c|}
\hline Entry & $\begin{array}{l}\text { Cat Pd } \\
(\mathrm{mol} \%)\end{array}$ & $\begin{array}{l}\text { Cat Cu } \\
(\mathrm{mol} \%)\end{array}$ & Base & Solvent & $\mathrm{T}\left({ }^{\circ} \mathrm{C}\right)$ & Yield(\%) $^{\mathrm{b}}$ \\
\hline 1 & 0.1 & 0.02 & DABCO & $\mathrm{H}_{2} \mathrm{O}$ & 50 & 8 \\
\hline 2 & 0.1 & 0.02 & $\mathrm{~K}_{2} \mathrm{CO}_{3}$ & $\mathrm{H}_{2} \mathrm{O}$ & 50 & 7 \\
\hline 3 & 0.1 & 0.02 & $t-\mathrm{BuOK}$ & $\mathrm{H}_{2} \mathrm{O}$ & 50 & 11 \\
\hline 4 & 0.1 & 0.02 & $\mathrm{~N}(\mathrm{Et})_{3}$ & $\mathrm{H}_{2} \mathrm{O}$ & 50 & 6 \\
\hline 5 & 0.1 & 0.02 & $\begin{array}{c}\mathrm{K}_{3} \mathrm{PO}_{4} \\
3 \mathrm{H}_{2} \mathrm{O}\end{array}$ & $\mathrm{H}_{2} \mathrm{O}$ & 50 & 9 \\
\hline 6 & 0.1 & 0.02 & DABCO & DMF & 50 & 87 \\
\hline 7 & 0.1 & 0.02 & $\mathrm{~K}_{2} \mathrm{CO}_{3}$ & DMF & 50 & 2 \\
\hline 8 & 0.1 & 0.02 & $t-\mathrm{BuOK}$ & DMF & 50 & 28 \\
\hline 9 & 0.1 & 0.02 & $\mathrm{Et}_{3} \mathrm{~N}$ & DMF & 50 & 36 \\
\hline 10 & 0.1 & 0.02 & $\begin{array}{c}\mathrm{K}_{3} \mathrm{PO}_{4} \\
3 \mathrm{H}_{2} \mathrm{O}\end{array}$ & DMF & 50 & 7 \\
\hline 11 & 0.1 & 0.02 & DABCO & $\mathrm{CH}_{3} \mathrm{CN}$ & 50 & 86 \\
\hline 12 & 0.1 & 0.02 & DABCO & $\mathrm{EtOH}$ & 50 & 0 \\
\hline 13 & 0.1 & 0.02 & DABCO & Toluene & 50 & 19 \\
\hline 14 & 0.1 & 0.02 & DABCO & DMF & 60 & 98 \\
\hline 15 & 0.05 & 0.01 & DABCO & DMF & 60 & 97 \\
\hline 16 & 0.025 & 0.005 & DABCO & DMF & 60 & 85 \\
\hline 17 & 0.05 & - & DABCO & DMF & 60 & 37 \\
\hline 18 & - & 0.01 & DABCO & DMF & 60 & 8 \\
\hline
\end{tabular}

[a] Reaction conditions: iodobenzene $(0.5 \mathrm{mmol})$, phenylacetylene $(0.75 \mathrm{mmol})$, base $(0.75$ mmol), solvent (1.5 mL), catalyst (see column). [b] GC yields.

Using the optimized reaction conditions, the Sonogashira reaction of structurally different aryl halides with alkynes were studied. Under the optimized reaction conditions, alkynylations of aryl iodides containing electron-donating groups such as methyl, isopropyl and methoxy and electron- withdrawing groups such as $\mathrm{NO}_{2}, \mathrm{Cl}$, and $\mathrm{F}$ as well as the heteroaromatic2iodothiophene, proceed very efficiently and produced the desired products in excellent yields (Table 2, entries 1-9). Also, reactions of aryl iodides with other alkynes such as propargyl alcohol and 4-ethynyltoluene, and 1-octyneproceed efficiently affording the corresponding 
alkynes in high to excellent yields (Table 2, entries 10-14). Furthermore, reactions of different aryl bromides as well as heterocyclic 5-bromopyrimidine and 2-bromopyridine proceed efficiently at $60-80{ }^{\circ} \mathrm{C}$ by increasing the loading to $0.2 \mathrm{~mol} \%$ Pd affording the desired products in high to excellent yields (Table 2, entries 15-23). It should be noted that reactions of 4nitrobromobenzene and 4-bromobenzaldehyde in the absence of Cu using Pd@MgO (Table 2, entries 24-25) and also in the absence of Pd using Cu@MgO (Table 2, entry 26) gave very low yields for desired products. Reactions of 4-chlorobenzaldehyde under the optimized reaction conditions was slow, therefore the reaction temperature was increased to $100{ }^{\circ} \mathrm{C}$ and $\mathrm{TBAB}(1$ eq) was added to the reaction mixture. Under these reaction conditions, the desired product was obtained in $61 \%$ yield (Table 2, entry 27). However, by increasing the temperature to $120^{\circ} \mathrm{C}$, the yield was improved to 94\% (Table 2, entry 28). Under this new reaction conditions, other aryl chlorides such as 4-chloronitrobenzene and 4-chlorobenzonitrile proceed well and gave 89-95\% yield for the corresponding products, respectively (Table 2, entries 29-30).

Table 2. Sonogashira-Hagihara reaction of terminal alkynes with aryl halides using $\mathrm{MgO} @ \mathrm{PdCu} .{ }^{\text {[a] }}$

$$
\begin{aligned}
& \text { MgO@PdCu } \\
& \begin{array}{c}
\mathrm{Ar}^{1} \mathrm{X}+\mathrm{R}^{2} \equiv \frac{\mathrm{Pd}(0.05 \mathrm{~mol} \%), \mathrm{Cu}(0.01 \mathrm{~mol} \%)}{\mathrm{DABCO}, \underset{\mathrm{DMF}}{\mathrm{DM}}} \mathrm{Ar}^{1}=\mathrm{R}^{2} \\
(\mathrm{X}=\mathrm{Br}, \mathrm{Cl}, \mathrm{I}) \quad \mathrm{C}-120 \mathrm{C}
\end{array}
\end{aligned}
$$

\begin{tabular}{lllllll}
\hline Entry & $\mathrm{R}^{2}$ & $\mathrm{Cat}(\mathrm{mol} \%)$ & $\mathrm{t}(\mathrm{h})$ & $\mathrm{T}\left({ }^{\circ} \mathrm{C}\right)$ & Yield(\%) $)^{\mathrm{b}}$ \\
\hline 1 & $\mathrm{C}_{6} \mathrm{H}_{5}$ & 0.05 & 24 & 60 & $97^{\mathrm{c}}$ \\
& & $\mathrm{C}_{6} \mathrm{H}_{5}$ & 0.05 & 15 & 60 & 95
\end{tabular}


<smiles>O=Cc1ccc(Br)cc1</smiles>

3

4

5

6

7

8

9

10

11

12

13<smiles>Clc1ccc(I)cc1</smiles>

14<smiles>Clc1ccc(I)cc1</smiles>

15<smiles>Cc1ccc(Br)cc1</smiles>

16<smiles>O=[N+]([O-])c1ccc(Br)cc1</smiles>

$\mathrm{C}_{6} \mathrm{H}_{13}$

$\mathrm{C}_{6} \mathrm{H}_{5}$

0.02

0.2

$\begin{array}{lllll}\mathrm{C}_{6} \mathrm{H}_{5} & 0.05 & 15 & 60 & 96\end{array}$

$\begin{array}{lllll}\mathrm{C}_{6} \mathrm{H}_{5} & 0.05 & 24 & 60 & 94\end{array}$

$\begin{array}{lllll}\mathrm{C}_{6} \mathrm{H}_{5} & 0.05 & 15 & 60 & 94\end{array}$

$\begin{array}{lllll}\mathrm{C}_{6} \mathrm{H}_{5} & 0.05 & 10 & 60 & 96^{\mathrm{C}}\end{array}$

$\begin{array}{lllll}\mathrm{C}_{6} \mathrm{H}_{5} & 0.05 & 24 & 60 & 97^{\mathrm{C}}\end{array}$

$\begin{array}{lllll}\mathrm{C}_{6} \mathrm{H}_{5} & 0.05 & 24 & 60 & 82\end{array}$

$\begin{array}{lllll}\mathrm{C}_{6} \mathrm{H}_{5} & 0.05 & 24 & 60 & 75\end{array}$

$\begin{array}{lllll}\mathrm{HOCH}_{2-} & 0.05 & 24 & 60 & 99^{\mathrm{c}}\end{array}$

$\begin{array}{lllll}\mathrm{HOCH}_{2-} & 0.05 & 24 & 60 & 98^{\mathrm{C}}\end{array}$

$\begin{array}{lllll}\mathrm{HOCH}_{2-} & 0.05 & 24 & 60 & 90\end{array}$

$\begin{array}{lllll}4-\mathrm{MeC}_{6} \mathrm{H}_{4} & 0.05 & 24 & 60 & 94\end{array}$

$\begin{array}{llll}0.05 & 24 & 60 & 88\end{array}$

17

$\mathrm{C}_{6} \mathrm{H}_{5}$

0.2

24

$60 \quad 70^{\mathrm{C}}$ 
18<smiles>O=Cc1ccc(Br)cc1</smiles>

19<smiles>BrCc1cncnc1</smiles>

20<smiles>FC(F)(F)c1cc(Br)cc(C(F)(F)F)c1</smiles>

21<smiles>Fc1ccc(Br)cc1</smiles>

22<smiles></smiles>

23<smiles>Cc1cccc2ccccc12</smiles>

24<smiles>O=[N+]([O-])c1ccc(Br)cc1</smiles>

$\mathrm{C}_{6} \mathrm{H}_{5}$<smiles>O=Cc1ccc(Br)cc1</smiles>

26<smiles>O=[N+]([O-])c1ccc(Br)cc1</smiles>

27<smiles>O=Cc1ccc(Cl)cc1</smiles>

28<smiles>O=Cc1ccc(Cl)cc1</smiles>

$\mathrm{C}_{6} \mathrm{H}_{5}$

$\mathrm{C}_{6} \mathrm{H}_{5}$

$\mathrm{C}_{6} \mathrm{H}_{5}$

$\mathrm{C}_{6} \mathrm{H}_{5}$

$\mathrm{C}_{6} \mathrm{H}_{5}$

$\mathrm{C}_{6} \mathrm{H}_{5}$

29<smiles>N#Cc1ccc(Cl)cc1</smiles>

30
0.2

0.2

0.2

0.2

0.2

0.2

0.2

24

60

$55^{\mathrm{c}, \mathrm{d}}$

0.2

0.2

24

120

$94^{\mathrm{c}, \mathrm{f}}$

0.2

24

24

48

100

$61^{\mathrm{c}, \mathrm{f}}$ 
of Cu using Pd@MgO. [e] Reaction in the absence of Pd using Cu@MgO. [f] Reactions using 1 eq of TBAB.

\subsection{Recycling of the catalyst}

Recovering and reusing of heterogeneous catalysts are very essential factors from economical and sustainable chemistry points of view. Along this line, we have studied recyclability of the catalyst for the reaction of iodobenzene and phenylacetylene under the optimized reaction conditions. For this purpose, after $24 \mathrm{~h}$ progress of the reaction, the catalyst was separated by centrifugation (6000 rpm), washed with ethyl acetate and after drying reused in another batch of reaction. By using this method, the catalyst was recovered and reused for 8 consecutive runs with very small decreasing in activity (97 to 90\%). However, the yield of the reaction was decreased to $84 \%$ in run 9 and to $63 \%$ in run 11 (Figure 7 ).

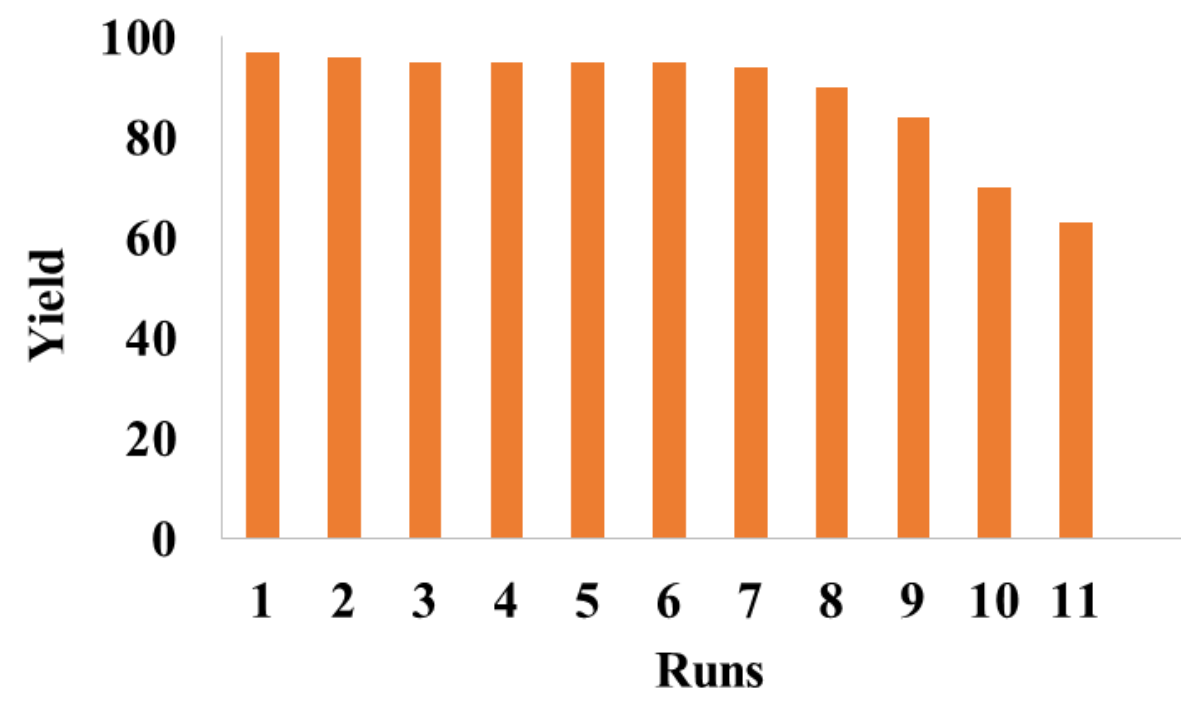

Figure 7: Recovering and reusing of the catalyst for the reaction of iodobenzene with phenyl acetylene. 
TEM images of the reused catalyst after 9 runs showed preservation of the catalyst structure and also the presence of nanoparticles with slight aggregation (Figure 8). Also, XPS analysis of reused catalyst after 9 runs showed in $\mathrm{Pd} 3 \mathrm{~d}$ and $\mathrm{Cu} 2 \mathrm{p}$ region showed very similar pattern to fresh catalyst (Figure 9). In the case of palladium, Pd(0), Pd(II) and $\operatorname{Pd}(\mathrm{IV})$ porcentage determined to be 38, 26 and 36\%, respectively. Furthermore, elemental EDS analyses showed the presence of $\mathrm{Pd}, \mathrm{Cu}, \mathrm{Mg}$, and $\mathrm{N}$ in the structure of the reused catalyst (Figure 4, ESI). 


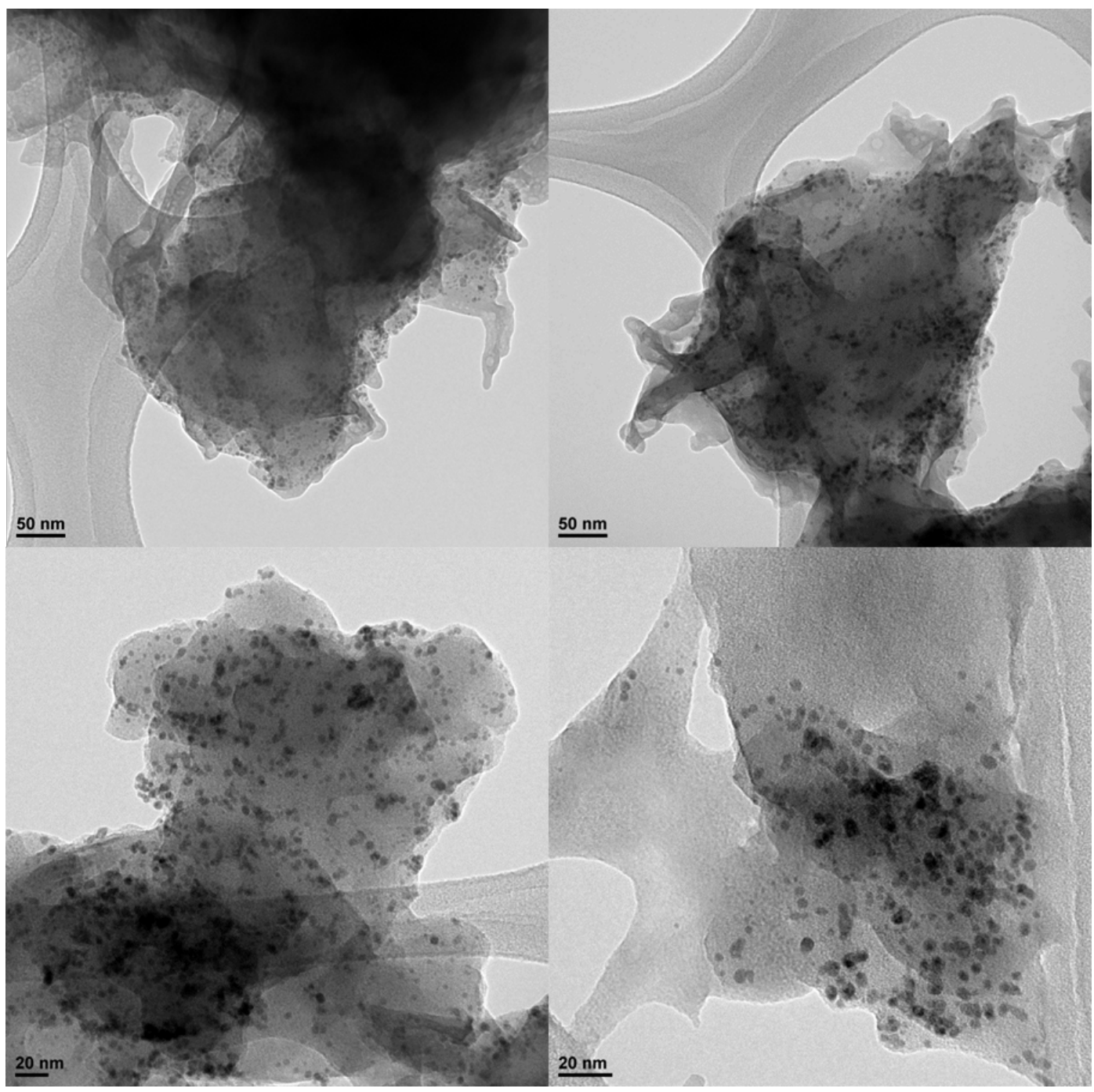

Figure 8: TEM images of the reused catalyst after the 9 run. 


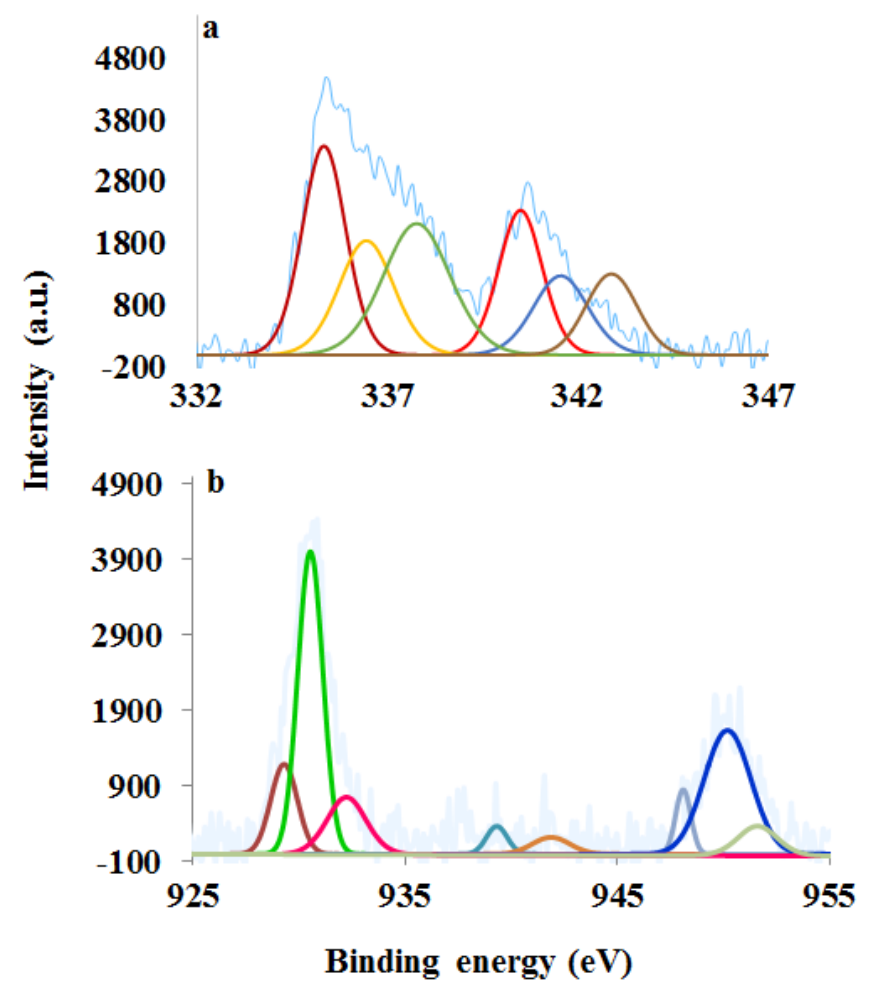

Figure 9: XPS spectra of reused catalyst after 9 run: a) Pd 3d and b) Cu 2p regions.

Finally, in order to find information about heterogeneous or homogeneous nature of the catalyst, two important tests were performed for the reaction of iodobenzene and phenylacetylene under the optimized reaction conditions. Initially, after $2 \mathrm{~h}$ stirring of the catalyst in DMF (2 mL) at 60 ${ }^{\circ} \mathrm{C}$, the catalyst was removed under hot filtration condition and iodobenzene, phenylacetylene and base were added to the obtained solution. The resulting mixture was stirred at $60{ }^{\circ} \mathrm{C}$ and GC analysis of the reaction after $24 \mathrm{~h}$ showed only 31\% conversion of iodobenzene to diphenylacetylene (Figure12). It should be noted that despite the fact that positive result of this hot filtration test is a strong proof for leaching or presence of homogeneous catalysis, a negative hot filtration test does not basically identify the presence of heterogeneous catalysis due to 
possibility of fast deactivation or redeposition of soluble active species. Thus further investigations are required for identifying the nature of true catalyst.

In another test we added polyvinylpyridine (PVP) (molar ratio to [Pd] -400) as a strong poison for homogeneous Pd species under optimized reaction conditions. GC analysis of reaction showed that reaction proceeded well with small interruption and gave $76 \%$ yield (Figure 10).

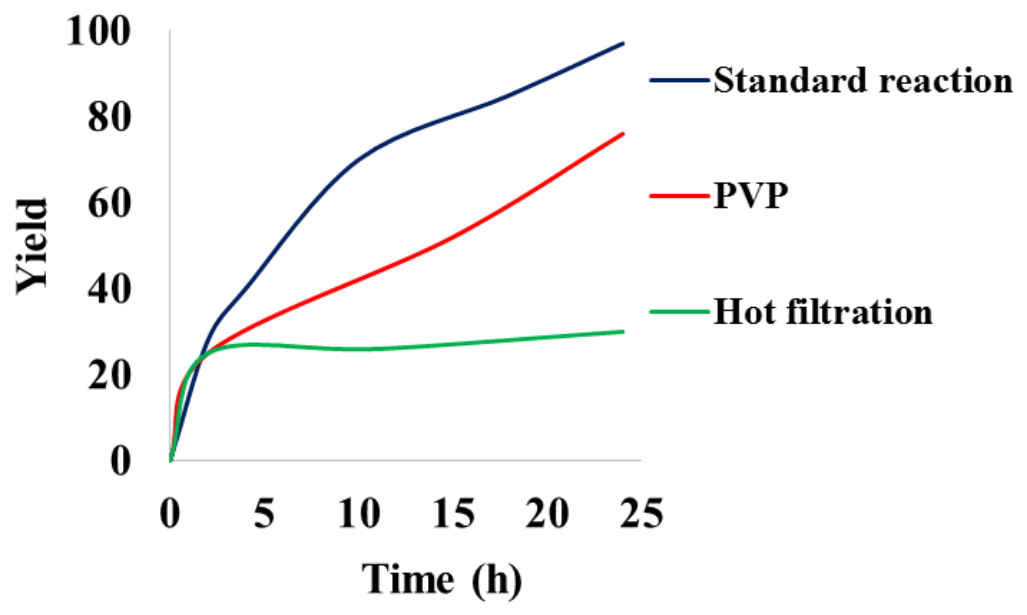

Figure 10: MgO@PdCu catalyzed reaction of iodobenzene with phenylacetylene in the presence of PVP and hot filtration conditions.

From the above described experiments, we deduce that the supported material MgO@PdCu catalyzes the Sonogashira reaction mostly under heterogeneous conditions.

\section{Conclusion}

In conclusion, we prepared new bimetallic PdCu supported on modified MgO catalyst using simple method and characterized by different techniques. This catalyst exhibits good catalytic efficiency in the Sonogashira reaction of aryl halides at $60-120{ }^{\circ} \mathrm{C}$. The presence of $\mathrm{Cu}$ was 
demonstrated to be crucial to obtain good yields. The catalyst was recovered and recycled using simple centerifugation and reused for 8 consecutive runs with very small decrease in activity. Heterogeneous properties of the catalyst was confirmed using addition of PVP and hot filtration test.

\section{Acknowledgements}

The authors are grateful to Institute for Advanced Studies in Basic Sciences (IASBS) Research Council and Iran National Science Foundation (INSF-Grant number of 95844587) for support of this work. C. Nájera is also thankful to the Spanish Ministerio de Economía y Competitividad (MINECO) (projects CTQ2013-43446-P and CTQ2014-51912-REDC), the Spanish Ministerio de Economía, Industria y Competitividad, Agencia Estatal de Investigación (AEI) and Fondo Europeo de Desarrollo Regional (FEDER, EU) (projects CTQ2016-76782-P and CTQ201681797-REDC), the Generalitat Valenciana (PROMETEOII/2014/017) and the University of Alicante for financial support.

\section{References}

[1] M. Lamblin, L. Nassar-Hardy, J. C. Hierso, E. Fouquet, F. X. Felpin, Adv. Synth. Catal., 352 (2010) 33.

[2] K. Sonogashira, Y. Tohda, N. Hagihara, Tetrahedron Lett., 16 (1975) 4467.

[3] R. Chinchilla, C. Nájera, Chem. Rev., 107 (2007) 874.

[4] R. Chinchilla, C. Nájera, Chem. Soc. Rev., 40 (2011) 5084.

[5] M. M. Heravi, S. Sadjadi, Tetrahedron, 65 (2009) 7761. 
[6] A. Kollhofer, H. Plenio, Chem. Eur. J., 9 (2003) 1416.

[7] R. Ciriminna, V. Pandarus, G. Gingras, F. Béland, P. D. Carà, M. Pagliaro, ACS Sustainable Chem. Eng., 1 (2013) 57.

[8] F. Bellina, M. Lessi, Synlett, 23 (2012) 773.

[9] E. Mas-Marzá, A. M. Segarra, C. Claver, E. Peris, E. Fernández, Tetrahedron Lett., 44 (2003) 6595.

[10] M. Poyatos, F. Márquez, E. Peris, C. Claver, E. Fernández, New J. Chem., 27 (2003) 425.

[11] K. Sonogashira, J. Organomet. Chem., 653 (2002) 46.

[12] F. Wagner, D. Comins, J. Org. Chem. 71 (2006) 8673.

[13] S. Frigoli, C. Fuganti, L. Malpezzi, L. Serra, Org. Proc. Res. Dev., 9 (2005) 646.

[14] M. Bakherad, Appl. Organomet. Chem. 27(2013)125.

[15] L. Yu, Z. Han, Y. Ding, Org. Process Res. Dev., 20 (2016) 2124.

[16] S. Thogiti, S. P. Parvathaneni, S. Keesara, J. Organomet. Chem., 822 (2016) 165.

[17] A. M. Mak, Y. H. Lim, H. Jong, Y. Yang, C. W. Johannes, E. G. Robins, M. B. Sullivan, Organometallics, 35 (2016) 1036.

[18] Karami, K., N. HaghighatNaeini, Turk. J. Chem., 39 (2015)1199.

[19] A. R. Hajipour, S. M. Hosseini, F. Mohammadsaleh, New J. Chem., 40 (2016) 6939.

[20] M. M. Sankar, N. Dimitratos, P. J. Miedziak, P. P. Wells, C. J. Kiely, G. J. Hutchings, Chem. Soc. Rev., 41 (2012) 8099. 
[21] G. Zhan, Y. Hong, V. T. Mbah, J. Huang, A. R. Ibrahim, M. Du, Q. Li, Appl. Catal., A, 439- 440 (2012) 179.

[22] J. Shi, Chem. Rev., 112 (2012) 2139.

[23] J. Mao, Y. Liu, Z Z. Chen, D. Wang, Y. Li, Chem. Commun., 50 (2014) 4588.

[24] M. Fernández-García, J. A. Anderson, G. L. Haller, J. Phys. Chem., 100 (1996) 16247.

[25] J. Batista, A. Pintar, M. Ceh, Catal. Lett., 43 (1997) 79.

[26] K. Mishra, N. Basavegowda, Y. R. Lee, RSC Adv., 6 (2016) 27974.

[27] M. Nasrollahzadeh, B. Jaleh, A. Ehsani, New J. Chem., 39 (2015) 1148.

[28] N. Barrabe's, J. Just, A. Dafinov, F. Medina, J. L. G. Fierro , J. E. Sueiras , P. Salagre, Y. Cesteros, Appl. Catal., B, 62 (2006) 77.

[29] J. Batista, A. Pintar, D. Mandrino, M. Jenko, V. Martin, Appl. Catal., A, 206 (2001) 113.

[30] B. P. Chaplin , E. Roundy, K. A. Guy, J. R. Shapley, C. J. Werth, Environ. Sci. Technol., 40 (2006) 3075.

[31] F. Deganello, L. F. Liotta, A. Macaluso, A. M. Venezia, G. Deganello, Appl. Catal., B, 24 (2000) 265.

[32] W. Gao, N. Guan, J. Chen, X. Guan, R. Jin, H. Zeng, Z. Liu, F. Zhang, Appl. Catal., B, 46 (2003) 341.

[33] M. Goyal, R. Nagahata, J. i. Sugiyama, M. Asai, M. Ueda, K. Takeuchi, Polymer, 40 (1999), 3237. 
[34] M. Hronec, K. Fulajtárová, I. Vávra, T. Soták, E. Dobročka, M. Mičušík, Appl. Catal., B, 181 (2016) 210.

[35] S. Jung, S. Bae, W. Lee, Environ. Sci. Technol. 48 (2014) 9651.

[36] J. Kugai, J. T. Miller, N. Guo, C. Song, J. Catal., 277 (2011) 46.

[37] L. Lu, L. Shen, Y. Shi, T. Chen, G. Jiang, C. Ge, Y. Tang, T. Chen, Y. Lu, Electrochimica. Acta, 85 (2012) 187.

[38] J. Sa', N. Barrabe’́s, E. Kleymenov, C. Lin, K. Fottinger, O. V. Safonova, J. Szlachetko, J. A. van Bokhoven, M. Nachtegaal, A. Urakawa, G. A. Crespof, G. Rupprechter, Catal. Sci. Technol., 2 (2012) 794.

[39] S. Sharma, K. C. Basavaraju, A. K. Singh, D. P. Kim, Org. Lett. 16 (2014) 3974.

[40] S. Sitthisa, T. Pham, T. Prasomsri, T. Sooknoi, R. G. Mallinson, D. E. Resasco, J. Catal., 280 (2011) 17.

[41] W. Tang, L. Zhang, G. Henkelman, J. Phys. Chem. Lett. 2 (2011) 1328.

[42] Y. Wang, J. Qu, H. Liu, C. Hu, Catal. Today, 126 (2007) 476.

[43] Y. Yoshinaga, T. Akita, I. Mikami, T. Okuhara, J. Catal., 207 (2002) 37.

[44] L. M. Tan, Z. Y. Sem, W. Y. Chong, X. Liu, K. Hendra, W. L. Kwan, C. L. K. Lee, Org. Lett., 15 (2013) 65.

[45] M. Gholinejad, N. Jeddi, B. Pullithadathil, Tetrahedron, 72 (2016) 2491.

[46] M.Gholinejad, J. Ahmadi, C. Nájera, M. Seyedhamzeh, F. Zareh, M. Kompany-Zareh, ChemCatChem, 9 (2017) 1442. 
[47] S. Diyarbakir, H. Can, O. Metin, ACS Appl. Mater. Interfaces, 7 (2015) 3199.

[48] A. Corma, H. García, A. Primo, J. Catal., 241 (2006) 123.

[49] W. Xu, H. Sun, B. Yu, G. Zhang, W. Zhang, Z. Gao, ACS Appl. Mater. Interfaces, 6 (2014) 20261.

[50] P. Cintas, G. Cravotto, E. C. Gaudino, L. Orio, L. Boffa, Catal. Sci. Technol., 2 (2012) 85.

[51] M. Gholinejad, J. Ahmadi, ChemPlusChem, 80 (2015) 973.

[52] E. M. Beccalli, G. Broggini, S. Gazzola, A. Mazza, Org. Biomol. Chem., 12 (2014) 6767.

[53] D. Sengupta, J. Saha, G. De, B. Basu, J. Mater.Chem. A, 2 (2014) 3986.

[54] M. Korzec, P. Bartczak, A. Niemczyk, J. Szade, M. Kapkowski, P. Zenderowska, K. Balin, J. Lelątko, J. Polanski, J. Catal., 313 (2014) 1.

[55] X. Wei, S. Yuanlong, G. Menghan, Z. Weiqiang, G. Ziwei, Chin. J. Org. Chem., 33 (2013) 820.

[56] S. Chouziera, M. Grubera, b. L. Djakovitch, J. Mol. Catal. A: Chem., 212 (2004) 43.

[57] S. Gu, D. Xu, W. Chen, Dalton Trans., 40 (2011) 1576.

[58] C. Rossy, J. Majimel, M. T. Delapierre, E. Fouquet, F. X. Felpin, J. Organomet. Chem., 755 (2014) 78.

[59] Y. Yoshinaga, T. Akita, I. Mikami, T. Okuharam, J. Catal., 207 (2002) 45.

[60] M. Chiba, M. N. Thanh, Y. Hasegawa, Y. Obora, H. Kawasakic, T. Yonezawa, Mater. Chem. C, 3 (2015) 514.

[61] K. H. Park, Y. W. Lee, Y. Kim, S. Kang, S. W. Han, Chem. Eur. J. 19 ( 2013 ) 8057. 
[62] S. Bai, Q. Shao, P. Wang, Q. Dai, X. Wang, X. Huang, J. Am. Chem. Soc. 139 (2017) 6830.

[63] Y. S. Feng, J. J. Ma, Y. M. Kang, H. J. Xu, Tetrahedron, 70 (2014) 6105.

[64] F. Cai, L. Yang, S. Shan, D. Mott, B. H. Chen, J. Luo, C. J. Zhong, Catalysts, 6 (2016) 96.

[65] Z. Y. Shih, C. W. Wang, G. Xu, H. T. Chang, J. Mater. Chem. A, 1 (2013) 4773.

[66] V. S. Marakatti, S. Ch. Sarma, B. Joseph, D. Banerjee, S. C. Peter, ACS Appl. Mater. Interfaces 9 (2017) 3615.

[67] K. Mori, H. Tanaka, M. Dojo, K. Yoshizawa, H. Yamashita, Chem. Eur. J. 21 (2015) 12092.

[68] A. Molnár, Platinum Metals Rev., 58 (2014) 93.

[69] M. Pagliaro, V. Pandarus, F. Béland, R. Ciriminna, G. Palmisano, P. D. Carà, Catal. Sci. Technol., 1 (2011) 736.

[70] M. Lamblin, L. Nassar-Hardy, J. C. Hierso, E. Fouquet, F. X. Felpin, Adv. Synth. Catal., $352(2010) 33$.

[71] A. Modak, J. Mondal, A. Bhaumik, Green Chem., 14 (2012) 2840.

[72] L. Djakovitch, F. X. Felpin, ChemCatChem, 6 (2014) 2175.

[73] L. Yin, J. Liebscher, Chem. Rev., 107 (2007) 133.

[74] Y. Uozumi, Catal. Surv. Asia, 9 (2005) 269.

[75] S. Sobhani, Z. Zeraatkara, F. Zarifi, New J. Chem., 39 (2015) 7076.

[76] C. E. Garrett, K. Prasad, Adv. Synth. Catal., 346 (2004) 889.

[77] S. Navalón, M. Álvaro, H. García, ChemCatChem., 5 (2013) 3460. 
[78] V. Polshettiwar, Á. Molnár, Tetrahedron, 63 (2007) 6949.

[79] D. Sahu, A. R. Silva, P. Das, Catal. Commun., 86 (2016) 32.

[80] A. Ghaderi, M. Gholinejad, H. Firouzabadi, Curr. Org. Chem., 20 (2016) 327.

[81] N. M. Julkapli, S. Bagher, Rev. Inorg. Chem., 36 (2015) 1.

[82] H. Hu, J. Lyu, J. Cen, Q. Zhang, Q. Wang, W. Han, J. Rui, X. Li, RSC Adv., 5 (2015) 63044.

[83] H. Borchert, B. Jürgens, V. Zielasek, G. Rupprechter , S. Giorgio, C. R. Henry, M. Bäumer, J. Catal., 247 (2007) 145.

[84] S. Naito, Y. Tanaka, Stud. Surf. Sci. Catal., 101 (1996) 1115.

[85] S. Li, C. Chen, E. Zhan, S. B. Liu, W. Shen, J. Mol. Catal. A: Chem., 304 (2009) 88.

[86] H. P. Aytam, V. Akula, K. Janmanchi, S. R. R. Kamaraju, K. R. Panja, J. Phys. Chem. B, 106 (2002) 1024.

[87] D. Ciuparu , A. Ensuque , F. Bozon-Verduraz, Appl. Catal., B, 326 (2007) 130.

[88] C. Dossi, A. Fusi, S. Recchia, M. Anghileri, R. Psaro, J. Chem. Soc., Chem. Commun., (1994) 1245.

[89] B. Huber, P. Koskinen, H. Häkkinen, M. Moseler, Nat. Mater., 5 (2006) 44.

[90] M. Lakshmi Kantam, R. Chakravarti, U. Pal, B. Sreedhar, S. Bhargava, Synth.Catal., 350 (2008) 822.

[91] M. L. Kantam, P. V. Reddy, P. Srinivas, A. Venugopal, S. Bhargava, Y. Nishina, Catal. Sci. Technol., 3 (2013) 2550. 
[92] P. V. Reddy, M. Annapurna, P. Srinivas, P. R. Likhar, M. L. Kantam, New J. Chem., 39 (2015) 3399.

[93] R. Rahi, M. Fang, A. Ahmed, R. A. Sánchez-Delgado, Dalton Trans., 41 (2012) 14490.

[94] M. L. Kantam, R. Kishore, J. Yadav, M. Sudhakar, A. Venugopal, Adv. Synth. Catal. 354 (2012) 663.

[95] H. Y. Kim, J. N. Park, G. Henkelman, J. M. Kim, ChemSusChem, 5 (2012) 1474.

[96] L. Huang, F. Chen, Y. Wang, P. K. Wong, Phys. Chem., 3 (2013) 21.

[97] F. Ringleb, M. Sterrer, H. J. Freund, Appl. Catal., A, 474(2014) 186.

[98] C. Barth, C. R. Henry, J. Phys. Chem. C, 113 (2009) 247.

[99] D. Ciuparu, A. Ensuque, F. Bozon-Verduraz, Appl. Catal., A, 326 (2007) 130.

[100] F. Frusteri, S. Freni, L. Spadaro, V. Chiodo, G. Bonura, S. Donato, S. Cavallaro, Catal. Commun., 5 (2004) 611.

[101] N. Kasper, A. Stierle , P. Nolte, Y. Jin-Phillipp, T. Wagner, D. G. de Oteyza, H. Dosch, Surf. Sci., 600 (2006) 2860.

[102] N. López, F. Illas, J. Phys. Chem. B, 10 (1998) 1430.

[103] M. Moseler, H. Hakkinen, U. Landman, Phys. Rev. Lett., 89 (2002) 176103.

[104] U. R. Pillai, E. Sahle-Demessie, Green Chem., 6 (2004) 161.

[105] X. Liu, M. Conte, S. Meenakshisundaram, Q. He, D. M. Murphy, D. Morgan, D. Knight, K. Whiston, C. J. Kiely, G. J. Hutchings, Appl. Catal., A, 504 (2015) 373. 
[106] L. X. Li, D. Xu, X. Q. Li, W. C. Liu, Y. Jia, New J. Chem., 38 (2014) 5445.

[107] K. Zhang, X. S. Li, Y. Duan, D. L. King, P. Singh, L. Li, Int. J. Green. Gas Control, 12 (2013) 351.

[108] F. Al-Hazmia, A. Umar, G.N. Dar, A.A. Al-Ghamdi, S.A. Al-Sayari, A. Al-Hajry,S.H. Kim, Reem M. Al-Tuwirqi, Fowzia Alnowaiserb, Farid El-Tantawy, J. Alloys Compd., 519 (2012) 4.

[109] R. Sívek, F. Bureš, O. Pytela, J. Kulhánek, Molecules 13 (2008) 2326.

[110] S. V. Myers, A. I. Frenkel, R. M. Crooks, Chem. Mater. 21 (2009) 4829.

[111] R. Ferrando, J. Jellinek, R. L. Johnston, Chem. Rev., 108 (2008) 845.

[112] Y. Xiong, W. Ye, W. Chen, Y. Wu, Q. Xu, Y. Yan, H. Zhang, J. Wu, D. Yang, RSC Adv., 7 (2017) 5806.

[113] F. Cai, L. Yang, S. Shan, D. Mott, B. H. Chen, J. Luo, C. J. Zhong, Catalysts 6 (2016) 96.

[114] Y. Zhang, X. He, J. Ouyang, H. Yang, Sci. Rep. 3, (2013) 1.

[115] A. S. Camacho, I. Martín-García, C. Contreras-Celedón, L. Chacón-García, F. Alonso, Catal. Sci. Technol., 7 (2017) 2262.

[116] M. Kim, S. Lee, K. Kim, D. Shin, H. Kim, H. Song, Chem. Commun., 50 (2014) 14938.

[117] C. Gonzalez-Arellano, R. Luque, D. J. Macquarrie, Chem. Commun., (2009) 1410.

[118] Y. H. Kim, D. K. Lee, H. G. Cha, C. W. Kim, Y. C. Kang, Y. S. Kang, J. Phys. Chem. B, 110 (2006) 24923. 
[119] H. Hou, M. Shang, F. Gao, L. Wang, Q. Liu, J. Zheng, Z. Yang, W. Yang,. ACS Appl. Mater. Interfaces, 8 (2016) 20128.

[120] M. Y. Lee, S. J. Ding, C. C. Wu, J. Peng, C. T. Jiang, C. C. Choud, Sensors and Actuators B 206 (2015) 584.

[121] J. Y. Park, Y. S. Jung, J. Cho, W. K. Choi, Appl. Surf. Sci., 252 (2006) 5877.

[122] T. Ghodselahi, M. A. Vesaghi, A. Shafiekhani, A. Baghizadeh, M. Lameii, Appl. Surf. Sci., 255 (2008) 2730.

[123] S. Yuan, J. Gu, Y. Zheng, W. Jiang, B. Liang, S. O. Pehkonen, J. Mater. Chem. A., 3 (2015) 4620.

[124] E. Mazzotta, S. Rella, A. Turco, C. Malitesta, RSC Adv., 5 (2015) 83164.

[125] Y. Zhang, Z. Xie, Z. Wang, X. Feng, Y. Wang, A. Wu, Dalton Trans., 45 (2016) 12653.

[126] N. Perchiazzi, S. Merlino, Eur. J. Mineral., 18 (2006) 787.

[127] S. Cui, X. Liu, Z. Sun, P. Du, ACS Sustainable Chem. Eng., 4 (2016) 2593.

[128] L. Yujie, T. Xiaofu, Z. Yanteng, L. Jin, L. Chengbin, M. Xinling, H. Yilong, H. Chunjin, W. Chunqing, Colloid Polym. Sci., 292 (2014) 715.

[129] V. Vellora, T. Padil, M. Černík, Int. J. Nanomedicine, 8 (2013) 889.

[130] M. Zhang, Z. Yan, J. Xie, Electrochimica Acta, 77 (2012) 237. 